\title{
Unique case of latent left ventricular obstruction in Takayasu arteritis
}

\author{
Toru Inami, ${ }_{1}^{1}$ Akihiro Shirakabe, ${ }^{2}$ Noritake Hata, ${ }^{2}$ Yoshihiko Seino ${ }^{1}$
}

'Department of Cardiology, Nippon Medical School Chiba-Hokusoh Hospital, Chiba, Japan

${ }^{2}$ Department of Intensive Care Unit, Nippon Medical School

Chiba-Hokusoh Hospital, Chiba, Japan

\section{Correspondence to}

Dr Toru Inami,

t-inami@nms.ac.jp

\section{DESCRIPTION}

Takayasu arteritis (TA) is a rare type of idiopathic large vessel vasculitis, which affects the aorta and its major branches ${ }^{1}$; however, clinical characteristics of cardiac hypertrophy in TA are not well known. A 73-year-old man with a medical history of TA was transferred to our department of intensive care unit for pulseless ventricular tachycardia. He was resuscitated with cardioversion and antiarrhythmic drugs.
The three-dimensional CT demonstrated a pathognomonic view of TA with stenosis of the carotid artery and subclavian artery (figure 1A). During the clinical examination, a cardiac MRI revealed marked left ventricular (LV) hypertrophy and outflow obstruction (figure $1 \mathrm{~B}$ and video 1 ). Left ventriculography confirmed an $\mathrm{LV}$ obstruction with apical ballooning (figure $2 \mathrm{~A}$ and video 2 ). LV pressure tracings showed a pressure gradient between LV

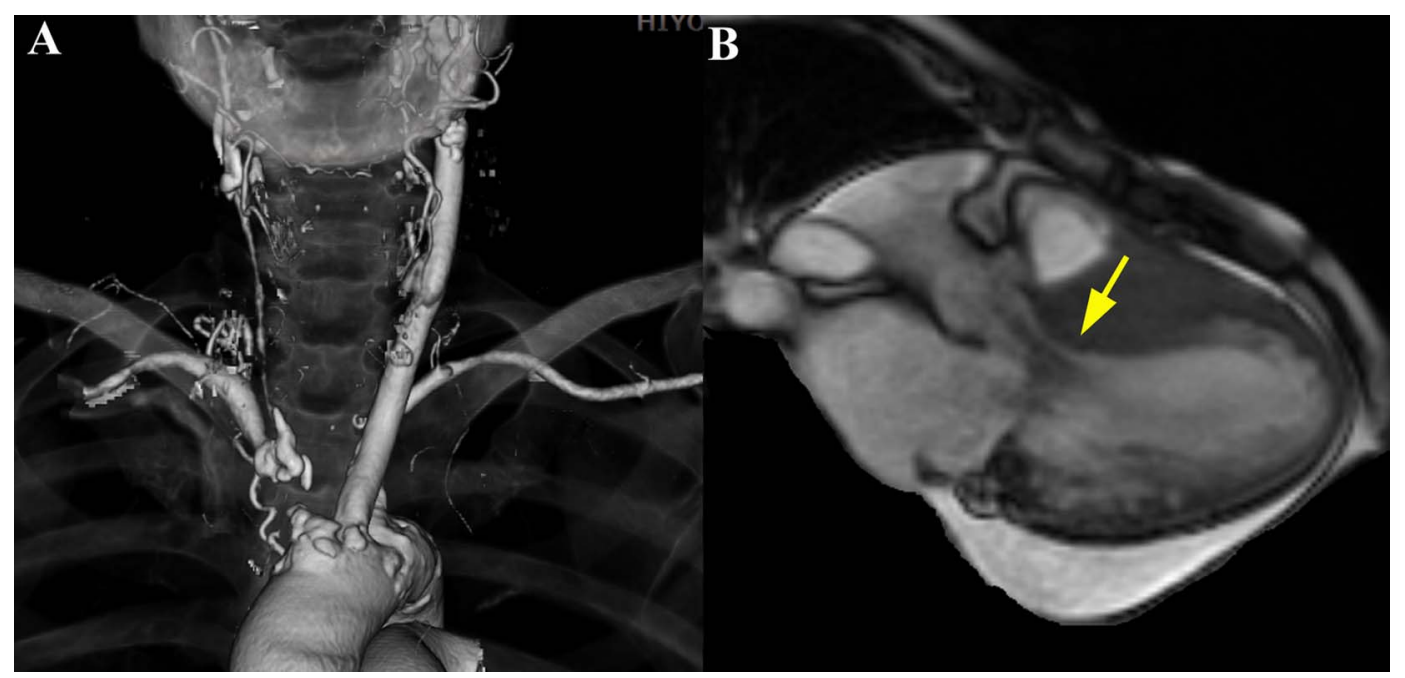

Figure 1 (A) The three-dimensional CT demonstrating stenosis of carotid artery and subclavian artery. (B) Cardiac MRI illustrating marked left ventricular hypertrophy and outflow obstruction expressed by acceralated blood flow indicated with yellow arrow.

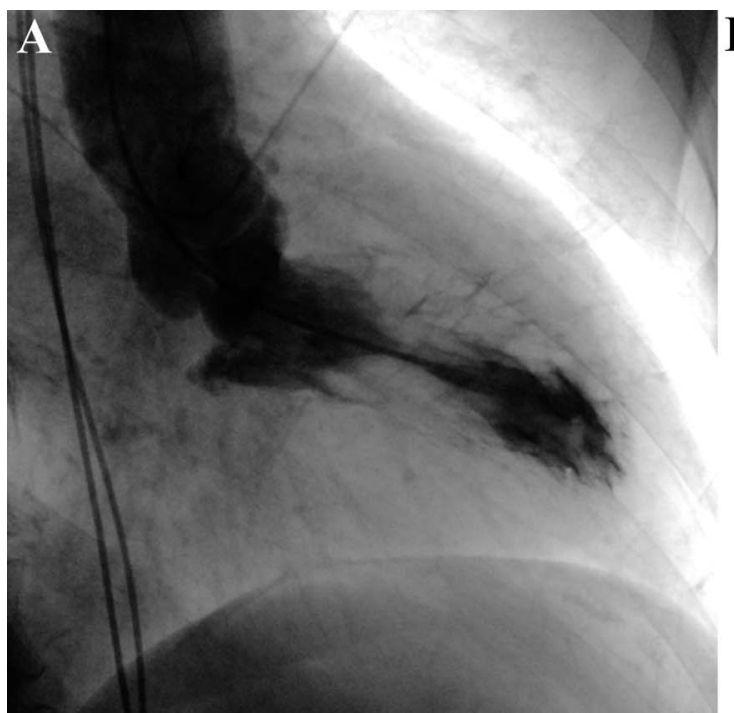

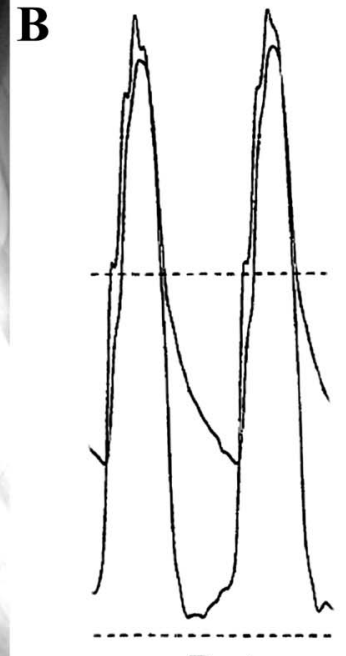

Rest

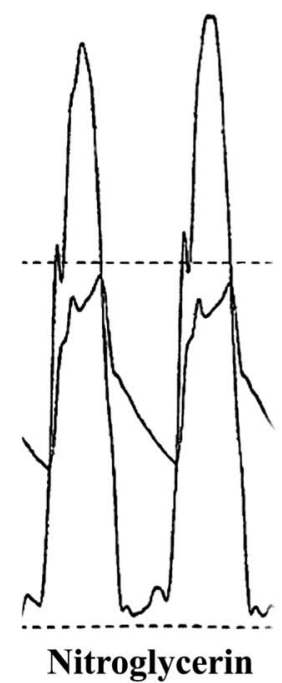

Figure 2 (A) Left ventriculography illustrating left ventricular obstruction with apical ballooning. (B) Left ventricular pressure tracings showing pressure gradient between left ventricle and aorta of $10 \mathrm{~mm} \mathrm{Hg}$ at rest in the left side. The right side image showing pressure gradient increased to $90 \mathrm{~mm} \mathrm{Hg}$ after trinitroglycerin administration. 


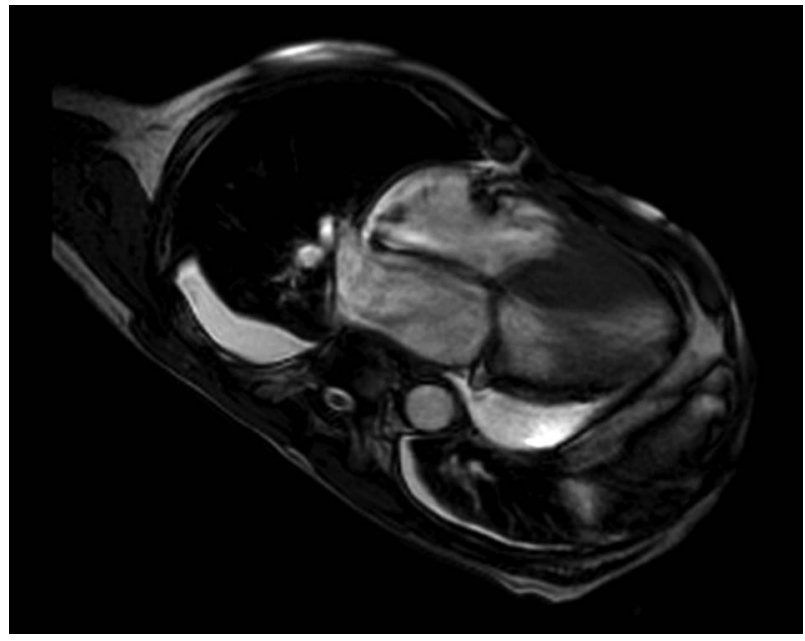

Video 1 Cardiac magnetic resonance imaging revealed left ventricular outflow obstruction which was expressed by acceralated blood flow.

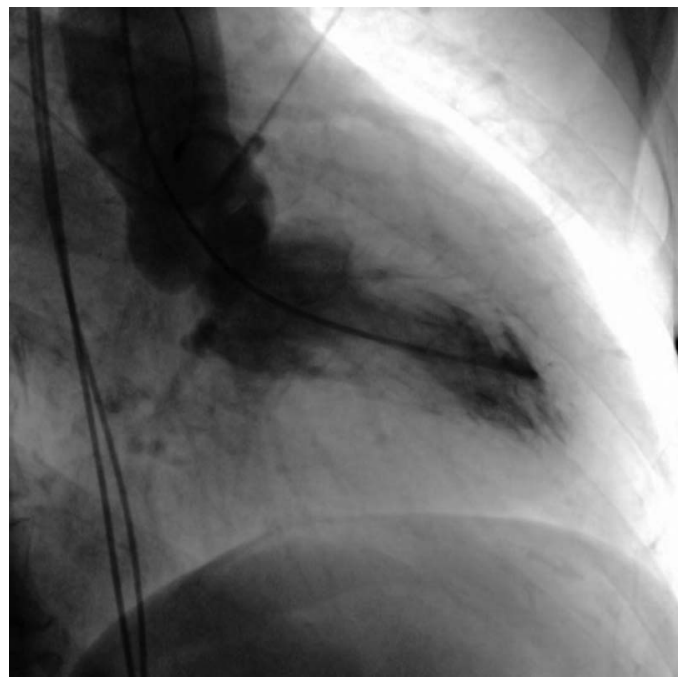

Video 2 Left ventriculography showed left ventricular obstruction with apical ballooning, and coronary angiography showed normal left coronary artery. and the aorta of $10 \mathrm{~mm} \mathrm{Hg}$ at rest; however, it increased to $90 \mathrm{~mm} \mathrm{Hg}$ after nitroglycerin administration (figure 2B), which is part of the classical description of hypertrophic obstructive cardiomyopathy. According to the necessity of an implantable cardioverter-defibrillator (ICD), dual chamber pacing with ICD was applied as the therapeutic strategy. ${ }^{2}$ It was known that concentric cardiac hypertrophy due to pressure overload occurred in $\mathrm{TA}^{3}$; however LV obstruction with cardiac hypertrophy in TA is a very rare case. In this case, measured systemic vascular resistance was $2693 \mathrm{dyn} \mathrm{s} / \mathrm{cm}^{5}$, which might mask the LV obstruction. This is a very suggestive case that latent $\mathrm{LV}$ obstruction is masked beneath overloaded pressure in a patient with TA with hypertrophic cardiomyopathy. Practical physicians should consider the possible existence of $\mathrm{LV}$ obstruction when patients with TA have hypertrophic cardiomyopathy.

\section{Learning points}

- Hypertrophic obstructive cardiomyopathy could be a differential diagnosis if any patient with takayasu arteritis (TA) presents with syncope.

- Concentric cardiac hypertrophy may occur due to overloaded pressure in TA.

- The presence of cardiac hypertrophy and left ventricular obstruction should be evaluated in periodic echocardiography during follow-up of patients with TA .

Contributors $\mathrm{TI}$ and YS contributed equally to the preparation and writing of the manuscript. AS and NH treated the patient in the intensive care unit.

Competing interests None.

Patient consent Obtained.

Provenance and peer review Not commissioned; externally peer reviewed.

\section{REFERENCES}

1 Numano F, Okawara M, Inomata $\mathrm{H}$, et al. Takayasu's arteritis. Lancet 2000;356:1023-5.

2 Minami Y, Kajimoto K, Kawana M, et al. Synergistic effect of dual chamber pacing and disopyramide in obstructive hypertrophic cardiomyopathy. Int I Cardiol 2010;141:195-7.

3 Terada Y, Mitsui T, Wanibuchi Y, et al. Concentric left ventricular hypertrophy late after aortic valve replacement in Takayasu's arteritis. I Thorac Cardiovasc Surg 1998:115:724-5

Copyright 2013 BMJ Publishing Group. All rights reserved. For permission to reuse any of this content visit

http://group.bmj.com/group/rights-licensing/permissions.

BMJ Case Report Fellows may re-use this article for personal use and teaching without any further permission.

Become a Fellow of BMJ Case Reports today and you can:

- Submit as many cases as you like

- Enjoy fast sympathetic peer review and rapid publication of accepted articles

- Access all the published articles

- Re-use any of the published material for personal use and teaching without further permission

For information on Institutional Fellowships contact consortiasales@bmjgroup.com

Visit casereports.bmj.com for more articles like this and to become a Fellow 